\title{
History-driven population structure and asymmetric gene flow in a recovering large carnivore at the rear-edge of its European range
}

\author{
A.A. Karamanlidis ${ }^{1,2} \cdot$ T. Skrbinšek ${ }^{3} \cdot$ M. de Gabriel Hernando ${ }^{4} \cdot$ L. Krambokoukis ${ }^{1}$ V. Munoz-Fuentes ${ }^{5,7} \cdot$ Z. Bailey $^{5}$. \\ C. Nowak ${ }^{5}$ - A.V. Stronen ${ }^{6}$
}

Received: 30 March 2017 / Revised: 21 September 2017 / Accepted: 25 October 2017 / Published online: 11 December 2017

(C) The Genetics Society 2018

\begin{abstract}
Understanding the mechanisms and patterns involved in population recoveries is challenging and important in shaping conservation strategies. We used a recovering rear-edge population of brown bears at their southernmost European range in Greece as a case study (2007-2010) to explore the recovery genetics at a species' distribution edge. We used 17 microsatellite and a mitochondrial markers to evaluate genetic structure, estimate effective population size and genetic diversity, and infer gene flow between the identified subpopulations. To understand the larger picture, we also compared the observed genetic diversity of each subpopulation with other brown bear populations in the region. The results indicate that the levels of genetic diversity for bears in western Greece are the lowest recorded in southeastern Europe, but still higher than those of other genetically depauperate bear populations. Apart from a complete separation of bear populations in eastern and western Greece, our results also indicate a considerable genetic sub-structuring in the West. As bear populations in Greece are now recovering, this structure is dissolving through a "recovery cascade" of asymmetric gene flow from South to North between neighboring subpopulations, mediated mainly by males. Our study outlines the importance of small, persisting populations, which can act as "stepping stones" that enable a rapid population expansion and recovery. This in turn makes their importance much greater than their numeric or genetic contribution to a species as a whole.
\end{abstract}

A. A. Karamanlidis, and T. Skrbinšek contributed equally to this work.

Electronic supplementary material The online version of this article (https://doi.org/10.1038/s41437-017-0031-4) contains supplementary material, which is available to authorized users.

A. A. Karamanlidis

akaramanlidis@gmail.com

1 ARCTUROS-Civil Society for the Protection and Management of Wildlife and the Natural Environment, Aetos, 53075 Florina, Greece

2 Department of Ecology and Natural Resource Management, Norwegian University of Life Sciences, NO-1432, Ås, Norway

3 Department of Biology, Biotechnical Faculty, University of Ljubljana, Večna pot 111, 1000 Ljubljana, Slovenia

4 C/Carnicerías 3, 2 I, 24003 León, Spain

5 Conservation Genetics Section, Senckenberg Research Institute and Natural History Museum Frankfurt, Clamecystrasse 12, 63571 Gelnhausen, Germany

6 Department of Chemistry and Bioscience, Aalborg University, Frederik Bajers Vej 7H, DK-9220 Aalborg Øst, Denmark

7 Present address: European Molecular Biology Laboratory, European Bioinformatics Institute, Wellcome Trust Genome Campus, Hinxton, Cambridge CB10 1SD, UK

\section{Introduction}

In the midst of the global biodiversity crisis (Butchart et al. 2010), even small conservation successes in the form of population recoveries [e.g., Asiatic lion (Panthera leo persica) (Singh and Gibson 2011)] may have a disproportional positive effect by serving as an example of how to move forward. However, equally important for effective conservation planning is understanding how such population recoveries take place (Simpfendorfer 2000); identifying patterns across taxa and environments may lead to more effective recovery plans and species management (Foin et al. 1998).

Species recoveries are influenced by various factors, including life history, habitat alteration and genetic responses to disturbance/exploitation (Hutchings and Reynolds 2004; Kerr and Deguise 2004; Hutchings 2005). Within the context of species recoveries, animal populations living at the edge of their range are important biological units for the study of ecology and evolution (Vergeer and Kunin 2012), as they can provide critical information on the evolutionary processes involved in the adaptation to local environments (Jump and Penuelas 2005). In view of the 
Fig. 1 Map indicating the location of five sampling areas for the collection of genetic samples from brown bears in Greece (2007-2010): PS South Pindos, $P C$ Central Pindos, $P N$ North Pindos, $V V$ Vitsi-

Varnoundas, $R D$ RodopiThe inset map indicates the general location of the study area in southeastern Europe, with the shaded areas indicating the approximate range of brown bears in Europe (according to Chapron et al. 2014); $\mathrm{A}=$ Dinaric-Pindos population, $\mathrm{B}=$ East Balkan population, $\mathrm{C}=$ Carpathian population

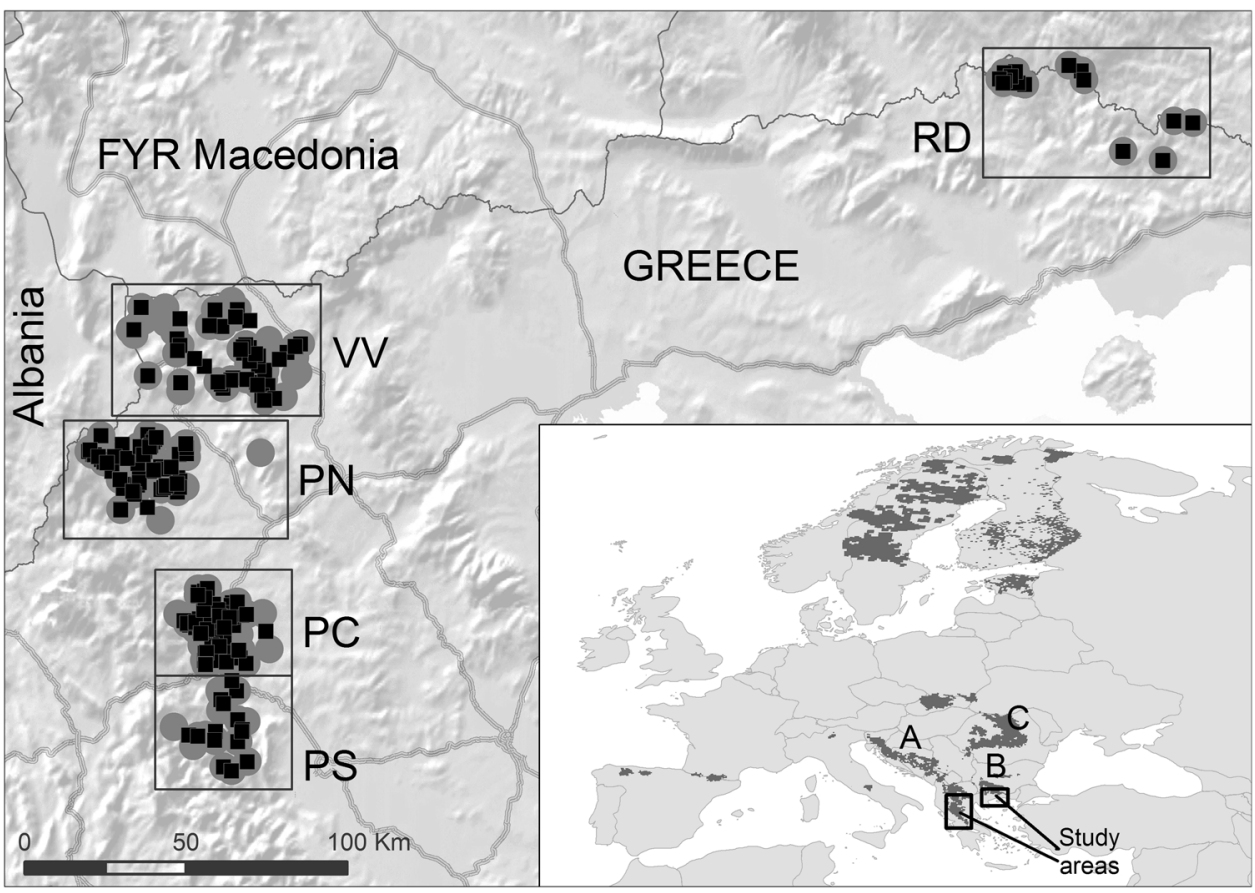

environmental changes taking place currently due to climate change, rear-edge (i.e., low-latitude limit) populations potentially carrying rare alleles and gene combinations important for successful adaptation to changing environmental conditions, could be disproportionately important for the long-term preservation of genetic diversity, phylogenetic history and the evolutionary potential of a species (Hampe and Petit 2005). The genetic consequences of species recoveries are still poorly understood; experimental studies have shown that genetic diversity during rapid range expansion may be preserved, often as a result of frequent long-distance dispersal events (Berthouly-Salazar et al. 2013; Mona et al. 2014).

The empirical relationships between the genetic processes and wildlife population recoveries are often ambiguous; currently recovering wild populations of large carnivores that have experienced extensive population bottlenecks in the recent past may prove to be useful model systems for investigating the (genetic) processes of population recovery (Hagen et al. 2015). In Europe brown bears (Ursus arctos) are distributed across large geographical regions (Kaczensky et al. 2013), with populations occurring in a wide range of ecologically distinct conditions and facing substantially different environmental and anthropogenic challenges and selection pressures to which they have to adapt accordingly (Swenson et al. 2007; Chevin and Lande 2011).

In Greece, brown bears reach their southern-most distribution on the European continent, which adds to their importance for European biodiversity. Bears in Greece survive in a fragmented, human-dominated landscape in two disjunct subpopulations: a larger one in the Pindos mountain range in the West, connected to bear populations in Albania and the Former Yugoslav Republic (FYR) of Macedonia, and a smaller one in the Rodopi Mountains in the East, connected to the East Balkan population in Bulgaria (Kaczensky et al. 2013) (Fig. 1). Bears in the West belong to the Dinaric-Pindos bear population (Fig. 1), which has been identified as one of the largest on the European continent (Kaczensky et al. 2013). The DinaricPindos bear population appears currently to be stable and/or locally increasing (Chapron et al. 2014), but this has not always been the case. At the beginning of the 20th century, the Dinaric-Pindos bear subpopulation had gone through a severe population bottleneck and was a fraction of its current size. Bears in Greece were no exception, with historical data suggesting a dramatic reduction in bear range and abundance throughout the 18th and 19th centuries due to human persecution (Servheen et al. 1999). Overall, brown bears in Greece are still considered endangered and are protected by law. Approximately since the beginning of this century encouraging signs of range expansion, such as extra-limital sightings (Karamanlidis et al. 2008) and population recovery have been recorded, mainly in the Pindos subpopulation; it is now estimated that $>450$ individuals survive in the country, approximately 410 in the Pindos Mountains and 30-40 in the Rodopi Mountains (Karamanlidis et al. 2015).

The ongoing population recovery, in conjunction with the current increase in human-bear conflicts (Karamanlidis et al. 2011), make the acquisition of genetic information a 
conservation priority for the species in Greece. Moreover, this situation offers a unique opportunity to study the recovery genetics of a rear-edge population of a large carnivore that has adapted to a human-dominated, Mediterranean landscape. In this first systematic, large-scale genetic study of brown bears in Greece, we explored how the historical decline in population range and size has impacted these bears, and how the current genetic status of the species is being affected by its ongoing recovery. We hypothesized that (a) we would find significant population structure, due to strong genetic drift effects in the remaining population fragments, but that (b) this structure would now be in the process of dissolving as population fragments currently recover and have started to reconnect. We also expected to find (c) low levels of genetic diversity compared to other, larger bear populations, due to isolation and edge distribution, and (d) signs of population expansion with directional gene flow and gradients of genetic diversity at the expansion front (Austerlitz et al. 1997; Le Corre and Kremer 1998; Excoffier et al. 2009).

Our results provide an improved understanding of the genetic status of brown bears in Greece, but also an account of a recovery process that may aid conservation efforts and the understanding of currently observed recoveries of large carnivores and other wildlife in Europe (Deinet et al. 2013; Chapron et al. 2014).

\section{Materials and methods}

\section{Study area and sampling methods}

The study was carried throughout the brown bear range in Greece. In western Greece, the study area extends over the approximately $250 \mathrm{~km}$-long section of the Pindos mountain range $\left(40^{\circ} 00^{\prime} \mathrm{N}, 21^{\circ} 03^{\prime} \mathrm{E}\right)$, reaching from the border of Albania and the FYR of Macedonia in the northwest, to central Greece. In eastern Greece, the study area extends over approximately $1700 \mathrm{~km}^{2}$ of brown bear range in the Rodopi Mountains $\left(41^{\circ} 25^{\prime}\right.$ N, $24^{\circ} 30^{\prime}$ E; Fig. 1).

Sampling efforts in the western range of the brown bear in Greece were based mainly on a monthly, non-invasive collection of genetic samples (i.e., hair) from wooden poles of the telephone and electricity network (Karamanlidis et al. 2007, 2010). Sampling was carried out in 2007-2010 in four sampling areas following the study design described in Karamanlidis et al. (2012; 2015). The four study areas [i.e., Vitsi-Varnoundas, North Pindos, Central Pindos, South Pindos; Fig. 1] were selected so as to cover the maximum of the core range of brown bears in western Greece and were separated from each other either by distance or/and geo-morphological features (e.g., extensive plains and valleys) and human infrastructure (e.g., major highways;
Fig. 1). The population estimates for Vitsi-Varnoundas, North, Central and South Pindos are 68 (23-203), 53 (22-112), 51 (29-95) and 10 (6-17) respectively (Karamanlidis et al. 2015). To increase sample size in western Greece, other genetic samples (i.e., blood, hair, scat, and tissue) were also used that were collected opportunistically during field surveys, concurrent telemetry studies, from rescued and rehabilitated animals and from animals killed in vehicle accidents. Sampling efforts in the eastern range of brown bears in Greece were based entirely on the opportunistic collection of genetic samples in 2007-2010.

\section{DNA extraction, microsatellite and mitochondrial analysis}

The laboratory procedures and protocols for DNA extraction, microsatellite analysis, error-checking and general quality assurance have been described in Karamanlidis et al. (2012; 2015). PCR products were run in an automated sequencer (ABI 310) and genotypes were determined using ABI Genescan and Genotyper version 2.1 software. Genotyping was performed by Wildlife Genetics International (Nelson, B.C., Canada).

A total of 60 samples, which were determined to belong to different individuals as per the microsatellite analysis, were used to sequence a $271 \mathrm{bp}$ stretch of the mitochondrial control region. Amplifications were performed in $15-\mu \mathrm{l}$ reactions containing 1x Gold Buffer (Applied Biosystems, Foster City, CA, USA), $2.5 \mathrm{mM} \mathrm{MgCl} 2,0.2 \mathrm{mM}$ dNTPs, $0.4 \mu \mathrm{M}$ forward primers, $0.4 \mu \mathrm{M}$ reverse primer and 0.027 U/ $\mu$ l AmpliTaq Gold DNA polymerase (Applied Biosystems). PCRs were performed in a T1 plus Thermocycler (Biometra GmbH, Göttingen, Germany) with an initial denaturation step of $95^{\circ} \mathrm{C}$ for $5 \mathrm{~min}$, followed by 38 cycles of $95^{\circ} \mathrm{C}$ for $30 \mathrm{~s}, 60^{\circ} \mathrm{C}$ for $30 \mathrm{~s}$, and $72{ }^{\circ} \mathrm{C}$ for $1 \mathrm{~min}$, and a final elongation step of $72{ }^{\circ} \mathrm{C}$ for $7 \mathrm{~min}$.

PCR products were purified by adding $4 \mu \mathrm{l}$ of Exonuclease I and $1.6 \mu \mathrm{l}$ of FastAP ${ }^{\mathrm{TM}}$ Thermosensitive Alkaline Phosphatase (Thermo Scientific, Waltham, MA USA) at 37 ${ }^{\circ} \mathrm{C}$ for $15 \mathrm{~min}$ followed by $80{ }^{\circ} \mathrm{C}$ for $15 \mathrm{~min}$. Purified PCR products were diluted 1:40 and both strands sequenced on an ABI3730 DNA Analyzer (Life Technologies GmbH, Darmstadt, Germany). Sequences from multiple PCRs were checked, edited and aligned using Geneious ver. 7.1.9 (Biomatters Limited), and alignments were re-checked visually.

\section{Data analyses}

CONVERT (Glaubitz 2004) was used to create input files for some of the population genetic programs employed in this study. To determine individual identity each sample 
was genotyped at 7 microsatellite loci: G1D, G10J, G10L (Paetkau and Strobeck 1994; Paetkau et al. 1998), G10C, G10P (Paetkau et al. 1995), MU51 and MU59 (Taberlet et al. 1997). Gender identification was established through the analysis of the amelogenin gene (Ennis and Gallagher 1994). Up to 10 additional loci were analyzed for each identified individual to increase the resolution of subsequent population genetic analyses. Tests for allelic dropout, presence of null alleles, and scoring errors caused by stutter peaks were performed with Micro-Checker version 2.2.3 (van Oosterhout et al. 2004) and the probability of identity among siblings $\left(P_{I D-S i b}\right)$ (Waits et al. 2001) was calculated using GIMLET ver. 1.3.2 (Valière 2002). In addition, the pairs of genotypes that matched at all but one, two or three loci (1-MM, 2-MM and 3-MM pairs) were identified using GenAlEx 6 (Peakall and Smouse 2006), and each group of matching genotypes was considered an individual animal. Analyses in LOSITAN (Antao et al. 2008) using stepwise and infinite allele models indicated three loci under divergent selection (or linked to loci under selection, as microsatellites are assumed selectively neutral) with $F_{S T}>0.25$. We examined population structure including and excluding these three loci (i.e., G10H, G10L, Mu59). As results were similar, we retained all 17 loci.

\section{Population structure}

To explore population structure and determine individual assignment to clusters, the Bayesian clustering method implemented in STRUCTURE ver. 2.3.4 (Pritchard et al. 2000) was used. 100,000 burn-in runs, followed by 1,000,000 Markov Chain Monte Carlo (MCMC) repetitions were used and $K=1-7$ possible population clusters were evaluated. We ran each parameter setting three times. The admixture model was used and allele frequencies were allowed to be correlated among populations. STRUCTURE Harvester ver. 0.6.94 (Earl and vonHoldt 2012) and CLUMPP ver. 1.1.2 (Jakobsson and Rosenberg 2007) were used to summarize the results, which included estimates for $\Delta K$ (Evanno et al. 2005); individual assignments were plotted using DISTRUCT ver. 1.1 (Rosenberg 2004). We then ran STRUCTURE five additional times for the optimal $K$ value, this time incorporating $90 \%$ probability intervals for cluster memberships $\left(q_{i}\right)$, and chose the results with the highest likelihood $\mathrm{L}(K)$ and lowest variance. To obtain meaningful population units where only individuals with a high degree of membership were considered, individuals were assigned to a cluster $k$ when $q_{\mathrm{i}} \geq 0.8$ to that cluster and probability intervals excluded membership to alternative clusters (Kopatz et al. 2014). Male bears have larger territories than females (Dahle and Swenson 2003), and separate analyses for males and females were performed to evaluate possible differences in population structure and the extent of admixture.

Population structure was explored also using spatial Principal Component Analysis (sPCA), a multivariate method for detecting spatial patterns in genetic variability (Jombart et al. 2008). It incorporates spatial information and yields scores that summarize both, the genetic variability and the spatial structure among individuals or populations. To correctly model geographic distances, the GPS location data for sample locations (WGS84) were projected into the metric Transverse Mercator projection (Greek grid). In the case of individuals that were identified in two or more georeferenced samples, the mean center of locations of these samples was calculated and used as the geo-reference for the animal's multilocus genotype. Spatial connectivity was modeled using the Delaunay triangulation (Upton and Fingleton 1985). We used the sPCA scree plot to visually determine the number of components to be interpreted, and Monte Carlo tests with 10,000 permutations were performed to test for the existence of global and local spatial structures (Jombart et al. 2008). The analysis was run in the $\mathrm{R}$ statistical environment ( $\mathrm{R}$ Core Team 2016) using the adegenet package (Jombart 2008).

To further evaluate genetic differentiation among bear subpopulations we calculated $F_{S T}$ (Weir and Cockerham 1984) in GENETIX v. 4.05.2 (Belkhir et al. 1996-2004) for pairs of subpopulations and estimated $95 \%$ confidence intervals by $N=1000$ bootstrap calculations. We first calculated values with all individuals, and subsequently made separate calculations for males and females.

In addition, maternally inherited population structure was explored by plotting mtDNA haplotypes on a map. To illustrate relationships among haplotypes, an unrooted parsimony network was constructed using TCS ver. 1.21 (Clement et al. 2000). Network figures were then generated using PopArt (Leigh and Bryant 2015) and manually edited to match the TCS network.

\section{Effective population size and genetic diversity}

Effective population size $\left(N_{e}\right)$ of bear subpopulations in Greece was estimated using the unbiased linkage disequilibrium (LDNe) estimator (Waples 2006). The method uses as a signal the expectation that in a finite population the loci that are otherwise unlinked will depart from linkage equilibrium. Extensive simulation-based testing has indicated that in small populations the method is reasonably precise and unbiased already at sample sizes of 25 individuals (Waples 2006; Waples and Do 2010). We applied the method using the LDNe program (Waples and Do 2008) following the recommendations of Waples and Do (2010), and excluded rare alleles with frequencies below 0.02 , or 
0.05 in the case of the Rodopi subpopulation (where the sample size was much smaller), respectively.

Genetic diversity parameters for each subpopulation were calculated using adegenet (Jombart 2008). Nuclear DNA diversity was measured as the number of alleles per locus $(A)$, the observed heterozygosity $\left(H_{o}\right)$ and Nei's unbiased expected heterozygosity $\left(H_{e}\right)$ (Nei 1978). Deviations from Hardy-Weinberg Equilibrium (HWE) were tested using the likelihood ratio-based exact test described by Engels (2009), as implemented in the R package HWXtest (Engels 2016). The Monte Carlo method was used when a full enumeration was not feasible, with the cut-off value set to $10^{9}$ tables. In order to compare the genetic diversity of bears in Greece with other well-studied bear populations, the reference population approach described in Skrbinšek et al. (2012c) was used. We calculated the heterozygosity ratio $\left(H_{e r}\right)$ and allelic richness ratio $\left(\mathrm{A}_{r t}\right)$ indices, and used them to compare the genetic diversity of Greek bears with the reference population, as well as with other populations for which these indices were calculated using the same reference population (Skrbinšek et al. 2012b). The data by Skrbinšek et al. (2012b) on brown bears in Slovenia was used as the reference population as this large dataset has already been used as a reference for comparisons of a large number of brown bear populations worldwide. The 10 loci that our study had in common with the reference dataset (i.e., G1A, G10C, G10D, G10J, G10L, G10M, G10P, Mu23, Mu50, Mu51, Mu59) were used, and R-scripts provided by Skrbinšek et al. (2012b) were applied to run the subsampling, with 1,000 random subsamples. We ran all analyses in $\mathrm{R}$. Because of the multiple resampling with replacement (bootstrapping) in the reference population approach, the errors of $H_{e r}$ and $A_{r t}$ should be normally distributed, and the Z-test (Sokal and Rohlf 1994) can be used to test for statistical significance of the difference between these indices in bears in Greece and other populations.

\section{Gene flow and Hardy-Weinberg dynamic subsampling (HWDS) analysis}

The Bayesian method developed by Wilson and Rannala (2003) and implemented in BAYESASS ver. 3.0.3 was used to infer gene flow between detected subpopulations. As too high or too low acceptance rates cause poor mixing of a MCMC, we adjusted the mixing parameters (i.e., the size of the proposed parameter change in each MCMC iteration) for allele frequencies, migration rates and inbreeding coefficients to get the acceptance rates of proposed moves between 0.2 and 0.4 (following the program author's recommendation). The program TRACER (Rambaut and Drummond 2003) was used to visually check MCMC for adequate mixing and convergence. We ran $10 \mathrm{MCMC}$ chains with different random seeds, $1.0 \mathrm{E}^{07}$ steps in each chain and $1.0 \mathrm{E}^{06}$ steps of burn-in. We calculated the Bayesian deviance for each chain to estimate model fit (Faubet et al. 2007) using the R script provided by Meirmans (2014) and discarded the chains with high deviance since non-converging chains do not provide useful information (Meirmans 2014). We averaged the results obtained across all remaining MCMC chains with similar deviance to calculate the final estimates of the migration rates.

To better understand the distribution of genetic diversity in bear populations in western Greece and the main drivers shaping it, we used the "moving window" concept to dynamically subsample genotypes according to their location. The specific intent of this Hardy-Weinberg Dynamic Subsampling analysis (HWDS) was to explore the size and direction of local deviations from Hardy-Weinberg proportions in a spatially explicit manner. To do this, we constructed a spatial path through the geographic extent of our data, and starting from one side of the path took a "window" subsample of $N_{g}$ neighboring genotypes/individuals (moving window-spatial "window" of $N_{g}$ genotypes along the path). We moved this moving window along the path in 1-genotype increments across all genotypes, calculating $H_{o}, H_{e}$ and the $P$-value of a HWE test for each window subsample. In general, this path can be of an arbitrary shape as long as it follows the spatial distribution of samples and/or landscape characteristics.

With discrete populations (i.e., the island model) and no gene flow the expectation would be that the window subsamples of genotypes (individuals) that include individuals from a single cluster (area) would be in HWE (i.e., Ho= $\mathrm{He}$ ), while the subsamples that would include individuals from neighboring clusters would show the Wahlund effect $(\mathrm{Ho}<\mathrm{He}$ ) (Wahlund 1928). Gene flow between the areas would cause deviations from this model, depending on its timing, direction, and magnitude. While a long-term, high gene flow would cause dissolving of population structure, recent short-term gene flow would cause either Wahlund effect with sampling of direct immigrants in the population (Ho $<\mathrm{He}$ ), or the "isolate breaking" effect (Wahlund 1928), where a recent reproduction of immigrants in the recipient population would cause heterozygote excess $(\mathrm{Ho}>\mathrm{He})$. This would persist for several generations until, in absence of new immigration, a new equilibrium would be established (Cornuet and Luikart 1996).

As bear habitat in western Greece is conveniently arranged in the north-south direction, the geographic northsouth axis was used as the moving window path, and parameters for each "window" of width $N_{g}=30$ genotypes were calculated. The analysis was programmed in $\mathrm{R}$ using functions from the adegenet package (Note: the $\mathrm{R}$ code for this analysis can be requested from T.S.). 
Table 1 Sampling efforts for the systematic, non-invasive and for the opportunistic collection of genetic samples from brown bears in western and eastern Greece (2007-2010) (VV VitsiVarnoundas, $P N$ North Pindos, $P C$ Central Pindos, PS South Pindos)

\begin{tabular}{lccccc}
\hline Sampling area & Visits & $\begin{array}{c}\text { Samples } \\
\text { collected }\end{array}$ & $\begin{array}{c}\text { Females } \\
\text { identified }\end{array}$ & $\begin{array}{c}\text { Males } \\
\text { identified }\end{array}$ & $\begin{array}{c}\text { Total } N \\
\text { identified }\end{array}$ \\
\hline VV & 1770 & 598 & 16 & 50 & 66 \\
PN & 2020 & 772 & 29 & 53 & 82 \\
PC & 4130 & 1025 & 35 & 69 & 104 \\
PS & 1401 & 267 & 3 & 18 & 21 \\
Opportunistic sampling & & 504 & 29 & 74 & 103 \\
western Greece & & 53 & 7 & 8 & 15 \\
Opportunistic sampling & & 3219 & 68 & 173 & 241 \\
eastern Greece & & & & \\
TOTAL & & &
\end{tabular}

\section{Results}

Between 2007-2010, we inspected 330 hair traps in western Greece 9321 times and collected 2662 hair samples. During the opportunistic sampling in western and eastern Greece we collected 504 and 53 samples, respectively (Table 1). None of the loci used in the study showed evidence of frequency distortion through large allele drop-outs or stutter peaks and no null alleles were identified. The probability that full siblings would have identical genotypes $\left(P_{S I B}\right)$ was 0.002 and in our final dataset there were no genotypes matching at all but one, two or three loci. In western Greece we identified 284 individuals during the systematic, noninvasive sampling and 103 individuals during the opportunistic sampling (Table 1). Several individuals identified during the systematic, non-invasive sampling were identified also during the opportunistic sampling and vice versa. In the Rodopi Mountains in eastern Greece we identified 15 individuals. In total, 324 individuals were identified, from which 241 individuals showed a full 17-locus and were therefore used for the following analyses.

\section{Population structure}

When all samples from Greece were used, STRUCTURE analysis indicated that the most likely number of population clusters was $K=3$ (Suppl. Figs. S1A, B). These three clusters were represented by bears sampled in the Rodopi, VitsiVarnoundas and Pindos (i.e., North, Central and South Pindos study areas combined) mountain regions, respectively (Fig. 2a). All 15 bears sampled in Rodopi were assigned with high probability $\left(q_{i} \geq 0.98\right)$ to one cluster. No individual from any other sampling area was assigned to this group or exhibited substantial proportion of ancestry to this group (Fig. 2a). We conducted a second STRUCTURE analysis excluding the Rodopi individuals to resolve population structure in western Greece. Here we used the LOCPRIOR model to incorporate location information (as outlined in the STRUCTURE manual) and 226 individuals from South, Central and North Pindos and Vitsi-Varnoundas. Our results suggested the presence of $K=3$ populations (Suppl. Figs. S1C, D) in western Greece (Fig. 2b). Additional results for individuals from western Greece, including cluster memberships and associated probability intervals are presented in Suppl. Note S1, Suppl. Fig. S2, and Suppl. Table S1.

Nine males were identified as migrants. Eight were putative immigrants from North Pindos: seven to Vitsi-Varnoundas and one to South Pindos. One individual sampled in VitsiVarnoundas was assigned to the South/Central Pindos cluster, and one female sampled in Vitsi-Varnoundas was a putative immigrant from North Pindos. Altogether 46\% (105/226) were designated as admixed, and the results were similar for males $(47 \%)$ and females (46\%). The findings from separate analyses for males and females (Suppl. Figs. S3-5) accorded with the STRUCTURE results for all bears.

For pairwise $F_{S T}$ analyses we considered the South/Central Pindos bears as one unit and performed calculations with all individuals sampled within the Rodopi, Vitsi-Varnoundas, North Pindos and South/Central Pindos areas. Although there was relatively weak support for a separate North Pindos cluster and only Rodopi bears emerged as an unequivocally distinct subpopulation, we include all four clusters to provide baseline values, and suggest they be interpreted with caution. The results for all bears, males and females were consistent with previous findings in showing clear differentiation between Rodopi bears and all other groups, where $F_{S T}$ values ranged from $0.132-0.160$ for all bears $(N=241), 0.127-0.140$ for males $(N=173)$ and $0.127-0.203$ for females $(N=68)$ (Table 2). In contrast, the highest value observed in pairwise comparisons for subpopulations in Western Greece was 0.063 between Vitsi-Varnoundas and South/Central Pindos females.

The sPCA results were consistent with the results obtained from STRUCTURE and provided additional insights into the spatial structuring of bears in western Greece. A Monte Carlo test with all the data from across Greece showed a clear indication of global structuring $(P<0.001)$, and the screeplot indicated one interpretable global component (Suppl. Fig. S6). The first component had by far the largest eigenvalue and showed a clear structuring between the Rodopi Mountains and the sampling areas in western Greece (Suppl. 
Fig. 2 STRUCTURE results for brown bears from Greecea STRUCTURE results for $N=$ 241 individuals from across Greece and $K=3$; b STRUCTURE results for $N=$ 226 individuals from western Greece and $K=3$. PS South Pindos; $P C$ Central Pindos; $P N$ North Pindos; $V V$ VitsiVarnoundas; $R D$ Rodopi a

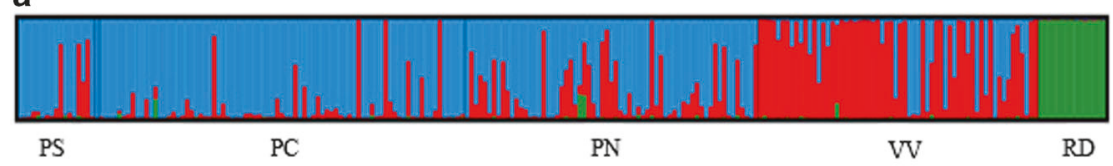

b

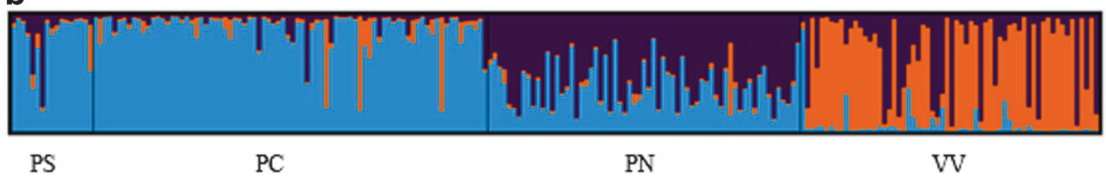

Fig. S7). There was some evidence of local structuring $(P=$ $0.013)$, but this was likely due to the geographic distance of the Rodopi samples from the other samples, and was not observable once the Rodopi data were removed. When the analyses were re-run without the strong signal of the Rodopi bears to get a clearer picture of the genetic structure in western Greece, the screeplot indicated two interpretable global components (Suppl. Fig. S8) and the Monte Carlo test indicated clear global structuring $(P<0.001)$, but there was no evidence of local structuring $(P=0.89)$. Component 1 , which had a much higher eigenvalue than the other components (eig = 2.74), indicated strong structuring between bears in Vitsi-Varnoundas and Pindos, where the results from the North Pindos area indicated presence of a genetic cline between Pindos and Vitsi-Varnoundas bears (Fig. 3a). Component 2 (eig $=1.33$ ) separated the North Pindos bears as a distinct group (Fig. 3b).

The structure described above for bears in western Greece, was consistent also with the results based on mtDNA sequences (Suppl. Fig. S9). Out of five haplotypes identified, two were most frequent in samples from VitsiVarnoundas $(N=13$ individuals analyzed), while three different ones were predominantly found in the samples from Pindos $(N=47)$. The two haplotypes mostly found in Vitsi-Varnoundas and those found in Pindos were separated by a minimum of five substitutions.

\section{Effective population size and genetic diversity}

We analyzed effective population size and genetic diversity for each subpopulation. Since South and Central Pindos belonged to the same population cluster, the data for these two areas were pooled (Table 3; per-locus and per-allele data are provided in the Suppl. Excel file). The effective population size $\left(N_{e}\right)$ estimates provided by LDNe showed narrow confidence intervals. The exception was the Rodopi area, where the number of samples was too low to provide a reliable estimate. While the $N_{e}$ estimates for the North Pindos $(93,95 \% \mathrm{CI}=65-149.8)$ and South/Central Pindos (106.2, 95\% CI $=80.5-148.7)$ clusters were similar, the $N_{e}$ estimates for the Vitsi-Varnoundas $(32.5,95 \% \mathrm{CI}=$
26.6-40.2) cluster were considerably lower. On the other hand heterozygosity in that area was higher than in the other areas in western Greece (paired samples t-test, $P=$ 0.004-0.017). Genetic diversity of the Rodopi bears was considerably higher than in the other Greek subpopulations (Table 3, Suppl. Table S2).

Levels of genetic diversity in bears from Greece differed considerably from those of other populations in the region (Table 4). Bears in Rodopi had high genetic diversity, comparable to that found in the large population in the Carpathian Mountains. On the other hand, genetic diversity of bears in western Greece was the lowest recorded in the Dinaric-Pindos population, but higher than that recorded in the Apennine bear population.

\section{Gene flow and HWDS analysis}

All BAYESASS runs were retained as they showed similar Bayesian deviance $($ mean $=18,093.66 ; \mathrm{SD}=0.555)$ and converged on nearly identical estimates. This analysis indicated an asymmetric gene flow pattern among the demes (subpopulations) in western Greece (Fig. 3a, b). There was considerable gene flow $(0.193, \mathrm{SE}=0.029)$ from North Pindos (PN) to Vitsi-Varnoundas (VV), but very little gene flow in the opposite direction (0.014, SE $=0.009)$. Similarly, there was considerable gene flow from South/ Central Pindos (PS + PC) towards North Pindos (NP) (0.193, $\mathrm{SE}=0.030)$ and low gene flow in the opposite direction (0.037, $\mathrm{SE}=0.016)$.

The HWDS analysis provided further insights into the gene flow patterns in western Greece (Fig. 3c). The results indicated that observed heterozygosity $(\mathrm{Ho})$ was generally higher than expected heterozygosity $(\mathrm{He})$, indicating the "isolate breaking" effect. The window subsamples composed entirely of samples from the Vitsi-Varnoundas area indicated an "isolate breaking" effect with a statistically significant departure from HWE in the northern part of the area (Fig. 3c). Moving towards the south and when window subsamples included individuals from the southern part of Vitsi-Varnoundas or individuals from both, the VitsiVarnoundas and North Pindos areas, the genotypes 
Table 2 Pairwise $F_{S T}$ values calculated for all bears, males and females sampled in the Rodopi Mountains (RD), VitsiVarnoundas (VV), North Pindos (PN), and South/Central Pindos (PS/C)

\begin{tabular}{lccc}
\hline All bears & $\mathrm{VV}(N=62)$ & $\mathrm{PN}(N=65)$ & $\mathrm{PS} / \mathrm{C}(N=99)$ \\
\hline $\mathrm{RD}(N=15)$ & $0.132(0.0991-0.1697)$ & $0.160(0.1159-0.2007)$ & $0.151(0.1104-0.1894)$ \\
$\mathrm{VV}(N=62)$ & & $0.026(0.0163-0.0369)$ & $0.034(0.0204-0.0483)$ \\
$\mathrm{PN}(N=65)$ & $\mathrm{VV}(N=50)$ & - & $0.020(0.0096-0.0335)$ \\
Males & $0.127(0.0810-0.1718)$ & $0.140(0.0813-0.1900)$ & $0.138(0.0956-0.1845)$ \\
$\mathrm{RD}(N=8)$ & & $0.019(0.0112-0.0279)$ & $0.0271(0.0157-0.0391)$ \\
$\mathrm{VV}(N=50)$ & & & $0.0198(0.0073-0.0332)$ \\
$\mathrm{PN}(N=44)$ & $\mathrm{VV}(N=12)$ & $\mathrm{PN}(N=21)$ & $\mathrm{PS} / \mathrm{C}(N=28)$ \\
Females & $0.127(0.0794-0.1811)$ & $0.203(0.1516-0.2547)$ & $0.178(0.1166-0.2415)$ \\
$\mathrm{RD}(N=7)$ & & $0.060(0.0275-0.0948)$ & $0.063(0.0354-0.0956)$ \\
$\mathrm{VV}(N=12)$ & & & $0.019(0.0038-0.0371)$ \\
$\mathrm{PN}(N=21)$ & & &
\end{tabular}

showed little departure from HWE. Window samples with individuals from the northern part of North Pindos appeared to be in HWE, while window samples from the southern part of North Pindos showed a considerable departure from HWE. Departure from HWE increased even more in window samples that included samples from both, North Pindos and Central Pindos, and the north of Central Pindos. As the window moved southward in Central and South Pindos, $\mathrm{Ho}$ again approached $\mathrm{He}$.

\section{Discussion}

In this first large-scale genetic study of the recovering brown bear population in Greece (Karamanlidis et al. 2015), we used a large number of samples and various complementary analytical methods to evaluate the genetic status of several subpopulations and to better understand their recovery and range expansion. Understanding the mechanisms and patterns involved in population recoveries is a challenge in conservation genetics (Excoffier et al. 2009; Petit 2011). Few population genetic studies have focused on this issue in nature, especially in wild animal populations at the (rear) edge of their range and over large areas, which makes the empirical relationship between genetic processes and population recoveries still rather ambiguous (but, see Herborg et al. 2007; Korkmaz et al. 2010; Short and Petren 2011; Hagen et al. 2015). In general, depending on the strength of drift, the dispersal potential of a species, the stability of local adaptations and the accumulated historical events (Vucetich and Waite 2003; Schmitt and Hewitt 2004), different patterns of genetic diversity and structure can be observed in edge vs. core populations (Korkmaz et al. 2010), with a considerable influence on the recovery potential (Arnaud-Haond et al. 2006). In our study we had the opportunity to explore many of these phenomena through real-world, empirical research.

\section{Population structure}

The results of our population structure analysis need to be interpreted in relation to the population history of the species, in both a wide and narrow geographic context. Bears in the Rodopi Mountains belong to the large East Balkan population (Frosch et al. 2014; Nowak et al. 2014); they are separated from bear subpopulations in western Greece by unsuitable habitat, and clearly stand as a separate population in the population structure analyses. It is possible that undetected dispersal events have occurred between the Rodopi Mountains and other subpopulations we studied; however, the lack of western individuals with high levels of Rodopi ancestry and vice versa in our sample of 241 bears suggests that eastern and western bears in Greece are effectively genetically isolated from each other.

In western Greece the situation is more diverse and dynamic through the presence of up to three distinct subpopulations (i.e., Vitsi-Varnoundas, North Pindos and South/Central Pindos), which accords with the hypothesis that isolation at the edge of a species' range favors genetic substructuring (Schaal and Leverich 1996). This structure likely formed when bear populations in Pindos were very small and isolated; while bears seem to have never gone extinct in North and South/Central Pindos, they seem to have survived in two small, isolated fragments. As small $N_{e}$ causes high genetic drift (Tremblay and Ackerman 2001), allelic frequencies in both fragments seem to have drifted apart, with population fragments becoming genetically distinct subpopulations. Recent population recovery and range expansion have likely resulted in population admixture of these two putative subpopulations. In Vitsi-Varnoundas, bears are either another example of a small isolated fragment that survived in the region or a relatively new occurrence; they are genetically distinct from Pindos bears and could have been formed by an expansion of bears from the FYR of Macedonia and/or Albania (Karamanlidis et al. 2014b). In this case the Vitsi-Varnoundas area could 


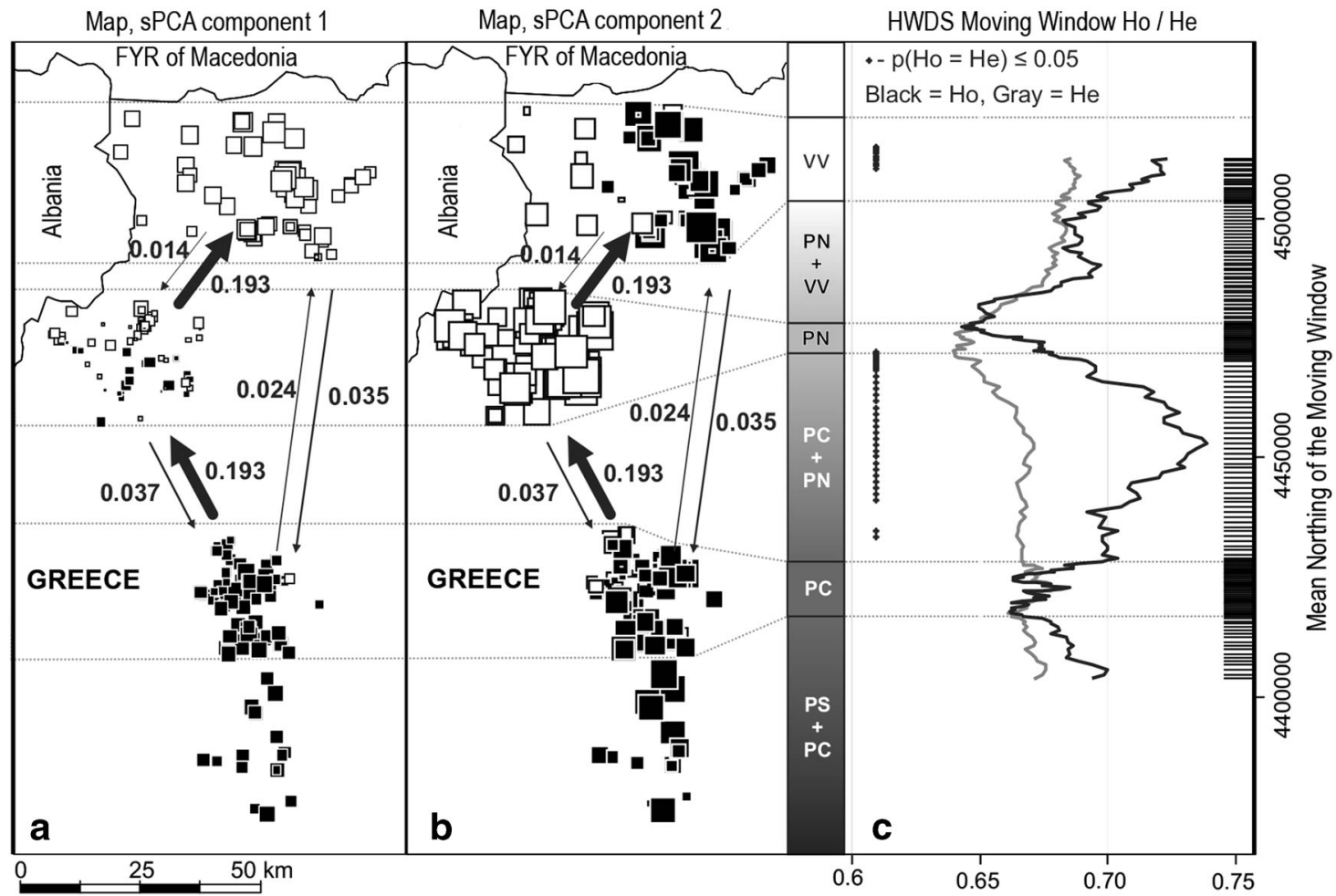

Fig. 3 Map of sPCA scores for components $1 \mathbf{a}$ and $2 \mathbf{b}$, BAYESASS gene flow estimates with direction (arrows) and the HWDS results $\left(N_{s}\right.$ $=30$ ) for bear subpopulations in western Greece $\mathbf{c}$. The numbers next to the arrows are gene flow estimates, and the thickness of each arrow is proportional to the estimate. The y-coordinate of each point on the HWDS graph is the mean northing coordinate of the window subsample, the density of the window subsamples corresponds to geographic clumping of samples in all three study areas and is shown with

be part of a "source-sink" system, where the reduced density of a peripheral population was met with migration from a core population, in this case probably the robust bear populations in the North Dinarics, in Bosnia and Herzegovina, Croatia and Slovenia (Skrbinšek et al. 2012a, c). The population structure results are supported by the STRUCTURE, $F_{S T}$, sPCA and mtDNA analyses and conform with our understanding of the population history of the species in the area, that is, of a bear population that has been drastically reduced in the recent past and that is now both, expanding in range and increasing in size (Kanellopoulos et al. 2006; Karamanlidis et al. 2008, 2012, 2015). Yet the population dynamics in western Greece are complex, and we have relatively few samples from the philopatric sex (i.e., females), which could lead us to underestimate population structure. Similar analyses of wolverines also found lower $F_{\mathrm{ST}}$ and $q$-values for the more mobile males (Cegelski et al. 2003) and we therefore recommend increasing sampling of females. Considering the challenges involved in identifying population structure characterized by clines rather than clusters (Jombart et al. 2008, Frosch et al. 2014), we have investigated Greek bears with several the "rug" at the right. The dotted horizontal lines indicate the composition of window subsamples-for example, the points on the HWDS graph between the "PN" lines are from the window subsamples in which all individuals have been sampled in the North Pindos area. $V V$ Vitsi-Varnoundas, $P N$ North Pindos, $P C$ Central Pindos, $P S$ South Pindos. Two areas (e.g., VV $+\mathrm{PN}$ ) indicate that the moving window subsamples include individuals from both areas

complimentary techniques (i.e., STRUCTURE, sPCA, HWDS analysis to visualize heterozygosity across space), but our results for this region should be viewed and interpreted cautiously.

\section{Effective population size and genetic diversity}

Effective population size $\left(N_{e}\right)$ is one of the most important evolutionary parameters of biological systems and of utmost relevance to biological conservation (Waples 2002). The LDNe approach used in our study to estimate $N_{e}$ assumes discrete generations, which in the case of the brown bear is clearly violated. However, Waples and Do (2010) discuss a reasonable conjecture that if the number of cohorts represented in a sample is approximately equal to the generation length, the LDNe estimate should roughly correspond to $N_{e}$ in a generation, which was later supported by Robinson and Moyer (2013). As our sample should correspond to a random sample of animals taken from the population, it should include several cohorts present in the population as they are represented in the wild, meaning that the absolute effective population size estimates of our study should be close to the 
Table 3 Estimates of effective population size and genetic diversity indices for different subpopulations of bears in Greece summarized for 17 microsatellite markers. $N$ number of individuals; $\mathrm{He}$ expected heterozygosity; $\mathrm{Ho}$ observed heterozygosity; $A$ number of alleles. $S E$ Standard Error; $N H W E$ the number of loci departing from the HWE with $P<0.05 ; N e$ effective population size, with $95 \%$ confidence interval in the parentheses

\begin{tabular}{llllllllll}
\hline Population $^{\mathrm{a}}$ & $N$ & $\mathrm{He}$ & $\mathrm{SE} \mathrm{He}$ & $\mathrm{Ho}$ & $\mathrm{SE} \mathrm{Ho}$ & $\mathrm{A}$ & $\mathrm{SE} A$ & NHWE & Ne (95\% CI) \\
\hline VV & 62 & 0.688 & 0.016 & 0.722 & 0.021 & 5.588 & 0.333 & 2 & $32.5(26.6-40.2)$ \\
$\mathrm{PN}$ & 65 & 0.658 & 0.024 & 0.676 & 0.027 & 5.471 & 0.259 & 1 & 93 (65-149.8) \\
PS/C & 99 & 0.680 & 0.020 & 0.681 & 0.023 & 5.765 & 0.304 & 5 & $106.2(80.5-148.7)$ \\
RD & 15 & 0.745 & 0.014 & 0.808 & 0.031 & 6.529 & 0.403 & 1 & $\mathrm{~b}$ \\
\hline
\end{tabular}

${ }^{a} V V$ Vitsi-Varnoundas, $P N=$ North Pindos, $P S / C$ South \& Central Pindos combined, $R D$ Rodopi

${ }^{\mathrm{b}}$ The sample size for the Rodopi area was too low to produce reliable estimates of effective population size actual number. As sampling was comparable in VitsiVarnoundas and in the Pindos areas, the relative $N_{e}$ estimates for these areas should be directly comparable regardless of their absolute value. All that said, recent population increases, and especially the high gene flow between subpopulations are certainly affecting the $N_{e}$ estimates, and these effects are difficult to predict. Also, while genetic structuring of Vitsi Varnoundas seems clear, structuring between North Pindos and Central/South Pindos is weaker and $N_{e}$ estimates for these areas are very similar, meaning that the $N_{e}$ estimate may in fact apply to the entire Pindos, not to individual subpopulations. All this means that the estimates should be interpreted cautiously; however, we believe that while the exact numbers may in fact not be precise, the general pattern of relatively low effective population sizes and a considerable difference between Pindos and Vitsi-Varnoundas still holds.

The $N_{e}$ estimates for the North Pindos and South/Central Pindos clusters were similar, and relatively large considering the estimated census population sizes. This corresponds well with population growth and expansion observed in the area (Karamanlidis et al. 2008, 2015) as the variance effective population size (estimated by the linkage disequilibrium method) will be driven upwards in a growing population (Crow and Kimura 1970). (Table 3). In contrast, the $N_{e}$ estimate for the Vitsi-Varnoundas area was considerably lower, which is in accordance with the assumption of either a very small remnant population or a rather recent population establishment from the North.

The legacy of the demographic history of bears in western Greece can also be observed in the comparison with the genetic diversity parameters of the other bear populations in the region. The combination of genetic isolation and population bottlenecks (i.e., reduced population size) (Lawton 1993) are expected to lead to a reduction in genetic diversity (Hoffmann and Blows 1994), such as is observed in bears in western Greece. The "yardstick" reference population method results indicate that, although genetic diversity of bears in different areas in western Greece was not as low as in, for example, the genetically depauperate Apennine bear population (Ciucci and Boitani 2008), it was not as high as in the other, much larger bear populations in the region, that is, the rest of the Dinaric-Pindos (Skrbinšek et al. 2012c), the East Balkan (Frosch et al. 2014) or the Carpathian population (Graban et al. 2013). At the other side of the country, in eastern Greece, genetic diversity of bears in the Rodopi Mountains, which belong to the large East Balkan bear population, was in comparison considerably higher.

\section{Gene flow and HWDS analysis}

Gene flow between small, endangered (sub)populations is important as it may counterbalance the effects of random genetic drift by increasing effective population size and minimizing possible stochastic (Frankham 1995; Storfer 1999) and inbreeding effects (Westemeier et al. 1998; Madsen et al. 1999). The gene flow pattern in our study was indicative of a population recovery process through reconnection of previously isolated population fragments. Gene flow between bear subpopulations in western Greece occurred generally in a South to North direction. Bears in South/Central Pindos did not receive much influx of individuals from the North, but seem to have contributed considerable gene flow towards North Pindos, where bears appear to be largely admixed. In contrast, bears in VitsiVarnoundas were mostly direct immigrants or local, and fewer individuals were admixed. This indicates that the process of subpopulations coming in contact is older in North Pindos (probably several generations), and relatively recent in Vitsi-Varnoundas, since not many immigrant bears have had time to establish and produce genetically detectable offspring. An explanation for this could be that bear recovery in South/Central Pindos triggered a faster recovery in North Pindos, which in turn enabled gene flow towards Vitsi-Varnoundas, effectively creating a "recovery cascade". 
Table 4 Comparison of genetic diversity of bears in Greece (in bold) with other brown bear populations in the region [values, except for the present study, are from Skrbinšek et al. (2012c) and Karamanlidis et al. (2014a, b)]

\begin{tabular}{lllllll}
\hline Area (population) & $N$ & $N C L$ & $A$ (S.E.) & $H e($ S.E. $)$ & $A r t($ S.E. $)$ & $H e r($ S.E. $)$ \\
\hline Romania1 (C) & 16 & 9 & $7.78(0.81)$ & $0.81(0.010)$ & $1.51(0.23)$ & $1.16(0.05)$ \\
Romania2 (C) & 109 & 13 & $8.46(0.57)$ & $0.80(0.014)$ & $1.34(0.15)$ & $1.09(0.04)$ \\
Rodopi, Greece (EB) & $\mathbf{1 5}$ & $\mathbf{1 0}$ & $\mathbf{6 . 2 7}(\mathbf{0 . 5 6})$ & $\mathbf{0 . 7 4}(\mathbf{0 . 0 2 0})$ & $\mathbf{1 . 2 0}(\mathbf{0 . 1 6})$ & $\mathbf{1 . 0 5}(\mathbf{0 . 0 5})$ \\
FYR Macedonia (DPSE) & 14 & 10 & $5.03(0.51)$ & $0.70(0.028)$ & $1.17(0.16)$ & $1.03(0.05)$ \\
Croatia (DPNW) & 156 & 12 & $7.58(0.54)$ & $0.74(0.028)$ & $1.17(0.14)$ & $1.01(0.05)$ \\
Slovenia (DPNW) & 513 & 20 & $6.68(0.41$ & $0.73(0.020)$ & $1.00(0.06)$ & $1.00(0.03)$ \\
N Slovakia (C) & 71 & 13 & $6.08(0.29)$ & $0.71(0.025)$ & $0.98(0.10)$ & $0.97(0.05)$ \\
Serbia (DPSE) & 10 & 11 & $5.25(1.42)$ & $0.67(0.162)$ & $0.96(0.07)$ & $1.08(0.12)$ \\
E Slovakia (C) & 16 & 13 & $5.23(0.22)$ & $0.65(0.028)$ & $0.96(0.09)$ & $0.91(0.05)$ \\
Central Slovakia (C) & 96 & 13 & $6.00(0.25)$ & $0.70(0.031)$ & $0.95(0.09)$ & $0.95(0.05)$ \\
Pindos N, Greece (DPSE) & $\mathbf{6 5}$ & $\mathbf{1 0}$ & $\mathbf{5 . 4 5}(\mathbf{0 . 3 7})$ & $\mathbf{0 . 6 6}(\mathbf{0 . 0 3 2})$ & $\mathbf{0 . 9 3}(\mathbf{0 . 1 0})$ & $\mathbf{0 . 9 0}(\mathbf{0 . 0 5})$ \\
Vitsi-Varnoundas, Greece (DPSE) & $\mathbf{6 2}$ & $\mathbf{1 0}$ & $\mathbf{5 . 3 6}(\mathbf{0 . 4 1})$ & $\mathbf{0 . 6 9}(\mathbf{0 . 0 1 9})$ & $\mathbf{0 . 9 2}(\mathbf{0 . 1 0})$ & $\mathbf{0 . 9 4}(\mathbf{0 . 0 4})$ \\
Pindos S/C, Greece (DPSE) & $\mathbf{9 9}$ & $\mathbf{1 0}$ & $\mathbf{5 . 2 7}(\mathbf{0 . 3 3})$ & $\mathbf{0 . 6 8}(\mathbf{0 . 0 2 9})$ & $\mathbf{0 . 8 8}(\mathbf{0 . 0 9})$ & $\mathbf{0 . 9 3}(\mathbf{0 . 0 5})$ \\
Apennines, Italy (A) & 17 & 9 & $2.44(0.24)$ & $0.44(0.069)$ & $0.63(0.10)$ & $0.47(0.05)$ \\
\hline
\end{tabular}

$N=$ number of individuals, $N C L=$ number of loci in common with the reference population (used for comparison), $A$ (S.E.) = allelic diversity for the common loci and standard error, $\mathrm{He}$ (S.E.) = expected heterozygosity for the common loci and standard error, $A_{r t}$ (S.E.) $=$ Allelic Ratio and standard error, $H_{e r}$ (S.E.) $=$ Heterozygosity Ratio and standard error

${ }^{a}$ Reference population

Populations: $C$ Carpathian, DPSE Dinaric-Pindos Southeast, DPNW Dinaric-Pindos Northwest, EB East Balkan, A Apennine
In addition, the relatively low admixture level and genetic distinctiveness of the Vitsi-Varnoundas individuals, coupled with relatively high genetic diversity despite low $N_{e}$ may indicate that this population might have received individuals from the North or persisted locally.

As one of the main advantages of BAYESASS is that it makes relatively few assumptions and can be used with populations that are not in migration-drift or HardyWeinberg equilibrium (Meirmans 2014). There has been however some debate in the literature about its pitfalls and advice on how to obtain reliable results (Faubet et al. 2007; Meirmans 2014). The method has been shown to perform better in cases of low migration rates and high differentiation between populations, and the results benefit from large per-population sample sizes and low number of populations in the analysis. While the latter is true in our study as we included only three populations with 62 to 99 animals each, differentiation between these populations was relatively low (Table 2), and estimated gene flow, although asymmetric, was high. On the other hand, repeated runs converged on nearly identical values, the non-migrant proportions were not close to the upper or lower bounds (Meirmans 2014) and all repeated runs had similar Bayesian deviance, which indicates that we did not have problems with convergence. Also, the HWDS analysis suggested that while there was considerable gene flow, it was relatively recent. This would decrease the estimated $F_{S T}$ values, but there is probably not much mating between animals with migrant ancestry yet, which is a critical issue that decreases the power of BAYESASS in high gene flow situations (Meirmans 2014). Considering all this we may expect a certain degree of bias in the gene flow estimates. However, the differences in estimated gene flow between different populations are very large, and even if the extreme bounds of the confidence intervals are considered, the conclusions drawn from this analysis remain the same.

The results of STRUCTURE and the assignment analysis indicate that gene flow in western Greece is mainly male mediated, a fact that is consistent with the larger home ranges and the greater dispersal propensity of (subadult) male bears (Swenson et al. 1998). Female brown bears are significantly more philopatric than males (Blanchard and Knight 1991; Mace and Waller 1997; Swenson et al. 1998; McLellan and Hovey 2001) and regular, long-distance female dispersal has been documented only within populations at pre-saturation densities (Swenson et al. 1998). This does not appear to be currently the case in Greece. Furthermore, given the fact that the flux of animals appears relatively large and considering the number of migrants and admixed animals (i.e., $>10 \%$ of the total population), it should be expected that the current gene flow has resulted not only in genetic effects but also in population fragments/ subpopulations becoming demographically dependent (Hastings 1993), which may be partially responsible for the demographic recovery of brown bears in western Greece (Karamanlidis et al. 2015). However, although male- 
mediated gene flow (as is currently mainly the case in western Greece) may maintain genetic variation in the long term, demographic persistence will be secured by femalemediated gene flow (Cegelski et al. 2006).

The HWDS analysis provides an informative view of the heterozygosity results and shows the interaction between the Wahlund's and "isolate breaking" effects, with the "isolate breaking" effect being generally more prominent (e.g., northern part of Vitsi-Varnoundas, southern part of North Pindos, area including samples from both, North and Central Pindos). This indicates that in these areas the "isolate breaking" process has probably been going on for a while, but is still relatively recent as the excess of heterozygotes expected when immigrants reproduce in the host population has still not dissolved, as it is expected to do in a couple of generations (Cornuet and Luikart 1996), if new gene flow barriers do not appear.

Heterozygosity results in the southern part of North Pindos are in accordance with the sPCA analysis; the PCA Component 1 map (Fig. 3a) indicates the North Pindos area as a "transition area" where gene flow forms a cline in genotypes between South/Central Pindos and VitsiVarnoundas. However, both the sPCA Component 2 map and STRUCTURE indicate genetic distinctiveness in North Pindos which is being admixed through immigration from South/Central Pindos.

On occasion (e.g., when window subsamples included individuals from the southern part of Vitsi-Varnoundas or individuals from both, Vitsi-Varnoundas and North Pindos) and contrary to expectations from the island model, the genotypes showed little departure from HWE, possibly because the diametrically opposite Wahlund's effect (which would be expected since animals from two clusters are sampled) and "isolate breaking" effects canceled each other out.

The population homogenization process resulting from the current gene flow will continue as long as there is at least one effective migrant per generation (Wright 1964), given differentiation values of less than $F_{S T}=0.2$ (Wang 2004). Occasional long-distance dispersals and relatively frequent shorter distance dispersals should not only maintain the total genetic diversity in this edge population, but also improve genetic diversity and decrease inbreeding in each population fragment/subpopulation (Bush et al. 2011), effectively improving the long-term viability of Greek bears. Therefore, maintaining and improving habitat connectivity will be extremely important for bear conservation in the region.

\section{Conclusions}

In the present study we have shown that a recovering bear population at the southern edge of its European range in western Greece is characterized by genetic sub-structuring and relatively low levels of genetic diversity. We also observed asymmetric gene flow from South to North, which is primarily maintained through dispersal of male individuals. The bear population in eastern Greece is divergent from bears in western Greece and, being a part of the larger East Balkan population, has high genetic diversity. The results of the study are in accordance with theoretical predictions (Brussart 1984; Hoffmann and Blows 1994) and empirical verification across a diverse range of taxa, including bears at the northern range of their European distribution (Hagen et al. 2015).

The results of our study are not only important for understanding the genetic mechanisms and patterns involved in the population recovery of a large carnivore, but also for understanding the genetic status of bears in Greece, predicting population recovery, and identifying national and international conservation priorities. It is assumed that over time, recovering animal populations may establish connectivity between subpopulations, leading to a decrease in population structure due to balanced gene flow and to an increase in genetic diversity (Excoffier et al. 2009; Ramakrishnan et al. 2010; Berthouly-Salazar et al. 2013; Mona et al. 2014). If the patterns of gene flow and increased admixture observed in our study persist, we may also expect population structure in western Greece to dissolve and within-population genetic diversity to increase, thus eventually augmenting the long-term viability of the population (Frankham 1996; Reed et al. 2003; Traill et al. 2007). Such genetic changes in natural systems may occur even within a single generation (i.e., in the case of bears approximately within one decade) (Christie et al. 2012; Hagen et al. 2015). Considering that the bear populations in Pindos and VitsiVarnoundas are separated by a highway (Fig. 1) that appears to be a significant barrier to large carnivore movement (Karamanlidis et al. 2016) and where $>15$ bears have been killed since 2009 in vehicle collisions (Karamanlidis 2012; unpublished data), it is important to continue monitoring the effects of the highway on the genetic status of large carnivores in the region. On a wider geographical scale and considering that overall genetic diversity of bears in western Greece is still lower than in the neighboring bear populations, conservation efforts should focus on establishing and maintaining habitat connectivity across FYR Macedonia, Albania, Montenegro and Serbia to effectively connect the Dinaric-Pindos population into a large, viable meta-population.

Last but not least, our study emphasizes the importance of small, persisting (sub)populations. Such relict populations or population fragments can act as "stepping stones", enabling a fast population expansion and recovery, and may initiate a "recovery cascade" if connectivity between fragments is re-established. This makes their importance much greater than their numeric or genetic contribution to a 
species' total population, and their protection should be considered a conservation priority.

\section{Data archiving}

Mitochondrial sequence data and sample information were deposited at the European Nucleotide Archive (ENA, EMBL-EBI) and can be retrieved via the DDBJ/EMBL/ GenBank database (accession numbers http://www.ebi.ac. uk/ena/data/view/LT962489-LT962548; study accession http://www.ebi.ac.uk/ena/data/view/PRJEB23330).

Acknowledgements We would like to thank the volunteers of ARCTUROS who helped in the field work. Sample collection in the Vitsi-Varnoundas area was carried out in cooperation with the Prespa National Forest Management Body and the Society for the Protection of Prespa. The assistance of Wildlife Genetics International in the generation of the microsatellite data, and especially of Renee Prive and David Paetkau is gratefully acknowledged. We thank Alexander Kopatz for valuable comments that improved the quality of our manuscript. Logistic and financial support for the study has been provided by the NGO ARCTUROS, the Hellenic Ministry of Rural Development and Food within the framework of the project " $1^{\text {st }}$ Genetic assessment of the brown bear population (Ursus arctos) in Greece", Egnatia S.A., Vodafone Greece and the Vodafone Group Foundation and an MHIRT grant to V.M.F and Z.B. A.V.S was supported by the Danish Natural Science Research Council (postdoctoral grant No. 1337-00007). All research activities were carried out under the research permits 98924/4791/17-9-2007 and 119628/ 1442 of the Hellenic Ministry of Environment, Energy and Climate Change, while samples were exported under the CITES permit 86729.

Author contributions A.A.K., T.S., and A.V.S. conceptualized and designed the research. A.A.K., M.d.G.H., and L.K. carried out the field sampling. A.A.K., V.M-F., and Z.B. conducted genetic analyses. A.A. K., T.S., V.M-F., and A.V.S. conducted data analyses. T.S. devised the HWDS approach. A.A.K., T.S., M.d.G.H., L.K., V.M-F., Z.B., C.N., and A.V.S. wrote the manuscript.

\section{Compliance with ethical standards}

Conflict of interest The authors declare that they have no competing interests.

\section{References}

Antao T, Lopes A, Lopes RJ, Beja-Pereira A, Luikart G (2008) LOSITAN: a workbench to detect molecular adaptation based on a $F_{S T}$-outlier method. BMC Bioinform 9:323

Arnaud-Haond S, Teixeira S, Massa SI, Billot C, Saenger P, Coupland G et al. (2006) Genetic structure at range edge: low diversity and high inbreeding in Southeast Asian mangrove (Avicennia marina) populations. Mol Ecol 15:3515-3525

Austerlitz F, Jung-Muller B, Godelle B, Gouyon PH (1997) Evolution of coalescence times, genetic diversity and structure during colonization. Theor Pop Biol 51:148-164

Belkhir K, Borsa P, Chikhi L, Raufaste N, Bonhomme F (1996) GENETIX 4.05, logiciel sous Windows TM pour la génétique des populations. Laboratoire Génome, Populations, Interactions, CNRS UMR 5000. Université de Montpellier II, Montpellier (France)-2004
Berthouly-Salazar C, Hui C, Blackburn TM, Gaboriaud C, Rensburg BJ, Vuuren BJ et al (2013) Long-distance dispersal maximizes evolutionary potential during rapid geographic range expansion. Mol Ecol Notes 22:5793-5804

Blanchard BM, Knight RR (1991) Movements of Yellowstone grizzly bears. Biol Cons 58:41-67

Brussart PF (1984) Geographic patterns and environmental gradients: the central-marginal model in Drosophila revisited. Ann Rev Ecol Syst 15:25-64

Bush KL, Dyte CK, Moynahan BJ, Aldridge CL, Sauls HS, Battazzo AM et al. (2011) Population structure and genetic diversity of greater sage-grouse (Centrocercus urophasianus) in fragmented landscapes at the northern edge of their range. Cons Genet 12:527-542

Butchart SHM, Walpole M, Collen B, van Strien A, Scharlemann JPW, Almond REA et al (2010) Global biodiversity: Indicators of recent declines. Science 328:1164-1168

Cegelski CC, Waits LP, Anderson NJ (2003) Assessing population substructure and gene flow in Montana wolverines (Gulo gulo) using assignment-based approaches. Mol Ecol 12:2907-2918

Cegelski CC, Waits LP, Anderson NJ, Flagstad O, Strobeck C, Kyle CJ (2006) Genetic diversity and population structure of wolverine (Gulo gulo) populations at the southern edge of their current distribution in North America with implications for genetic viability. Cons Genet 7:197-211

Chapron G, Kaczensky P, Linnell JDC, von Arx M, Huber D, Andrén H et al (2014) Recovery of large carnivores in Europe's modern human-dominated landscapes. Science 346:1517-1519

Chevin LM, Lande R (2011) Adaptation to marginal habitats by evolution of increased phenotypic plasticity. J Evol Biol 24:1462-1476

Christie MR, Marine ML, French RA, Blouin MS (2012) Genetic adaptation to captivity can occur in a single generation. Proc Nat Acad Sci USA 109:238-242

Ciucci P, Boitani L (2008) The Apennine brown bear: A critical review of its status and conservation problems. Ursus 19:130-145

Clement M, Posada D, Crandall KA (2000) TCS: a computer program to estimate gene genealogies. Mol Ecol 9:1657-1660

Cornuet JM, Luikart GL (1996) Description and power analysis of two tests for detecting recent population bottlenecks from allele frequency data. Genetics 144:2001-2014

Crow JF, Kimura M (1970) An introduction to population genetics theory. Burgess Publishing Company, Minneapolis, Minnesota

Dahle B, Swenson JE (2003) Home ranges in adult Scandinavian brown bears (Ursus arctos): effect of mass, sex, reproductive category, population density and habitat type. J Zool 260:329-335

Deinet S, Ieronymidou C, McRae L, Burfield IJ, Foppen RP, Collen B et al. (2013) Wildlife comeback in Europe: The recovery of selected mammal and bird species. In: Final report to Rewilding Europe by ZSL, BirdLife International and the European Bird Census Council ZSL, London, UK

Earl DA, vonHoldt BM (2012) STRUCTURE HARVESTER: a website and program for visualizing STRUCTURE output and implementing the Evanno method. Con Gen Res 4:359-361

Engels B (2016) HWxtest: exact tests for Hardy-Weinberg proportions. R package version 1.1.7

Engels WR (2009) Exact tests for Hardy-Weinberg proportions. Genetics 183:1431-1441

Ennis S, Gallagher T (1994) A PCR based sex determination assay in cattle based on bovine Amelogenin locus. Anim Genet 25:425-427

Evanno G, Regnaut S, Goudet J (2005) Detecting the number of clusters of individuals using the software STRUCTURE: a simulation study. Mol Ecol 14:2611-2620 
Excoffier L, Foll M, Petit RJ (2009) Genetic consequences of range expansions. Ann Rev Ecol, Evol, Syst 40:481-501

Faubet P, Waples RS, Gaggiotti OE (2007) Evaluating the performance of a multilocus Bayesian method for the estimation of migration rates. Mol Ecol 16:1149-1166

Foin TC, Pawley AL, Ayres DR, Carlsen TM, Hodum PJ, Switzer PV (1998) Improving recovery planning for threatened and endangered species. BioScience 48:177-184

Frankham R (1995) Inbreeding and extinction: a threshold effect. Cons Biol 9:792-799

Frankham R (1996) Relationship of genetic variation to population size in wildlife. Cons Biol 10:1500-1508

Frosch C, Dutsov A, Zlatanova D, Valchev K, Reiners TE, Steyer K et al. (2014) Noninvasive genetic assessment of brown bear population structure in Bulgarian mountain regions. Mammal Biol 79:268-276

Glaubitz JC (2004) Convert: a user-friendly program to reformat diploid genotypic data for commonly used population genetic software packages. Mol Ecol Notes 4:309-310

Graban J, Kisková J, Pepich P, Rigg R (2013) Genetic analysis for geographic isolation comparison of brown bears living in the periphery of the Western Carpathians Mountains with bears living in other areas. Open J Gen 3:174-182

Hagen SB, Kopatz A, Aspi J, Kojola I, Eiken HG (2015) Evidence of rapid change in genetic structure and diversity during range expansion in a recovering large terrestrial carnivore. Proc R Soc B 282:20150092

Hampe A, Petit RJ (2005) Conserving biodiversity under climate change: the rear edge matters. Ecol Lett 8:461-467

Hastings A (1993) Complex interactions between dispersal and dynamics lessons from coupled logistic equations. Ecology 74:1362-1372

Herborg LM, Weetman D, van Oosterhout C, Hanfling B (2007) Genetic population structure and contemporary dispersal patterns of a recent European invader, the Chinese mitten crab. Eriocheir Sin Mol Ecol 16:231-242

Hoffmann AA, Blows MW (1994) Species borders-ecological and evolutionary perspectives. Trends Ecol Evol 9:223-227

Hutchings JA, Reynolds JD (2004) Marine fish population collapses: consequences for recovery and extinction risk. BioScience 54:297-309

Hutchings JA (2005) Life history consequences of overexploitation to population recovery in Northwest Atlantic cod (Gadus morhua). Can J Fish Aqua Scie 62:824-832

Jakobsson M, Rosenberg NA (2007) CLUMPP: a cluster matching and permutation program for dealing with label switching and multimodality in analysis of population structure. Bioinformatics 23:1801-1806

Jombart T (2008) adegenet: a R package for the multivariate analysis of genetic markers. Bioch Gen 10:149-163

Jombart T, Devillard S, Durfour A-B (2008) Revealing cryptic spatial patterns in genetic variability by a new multivariate method. Heredity 101:92-103

Jump AS, Penuelas J (2005) Running to stand still: adaptation and the response of plants to rapid climate change. Ecol Lett 8:1010-1020

Kaczensky P, Chapron G, von Arx M, Huber Đ, Andrén H, Linnell J. (2013) Status, management and distribution of large carnivores bear, lynx, wolf \& wolverine-in Europe-Part 1, 1-72.

Kanellopoulos N, Mertzanis G, Korakis G, Panagiotopoulou M (2006) Selective habitat use by brown bear (Ursus arctos L.) in northern Pindos, Greece. J Biol Res 5:23-33

Karamanlidis AA (2012) Monitoring the effects of the "Egnatia" highway (Section Siatista - Kastoria - Krystallopygi) on brown bears in northern Greece. Int Bear News 21:24-25
Karamanlidis AA, Drosopoulou E, de Gabriel Hernando M, Georgiadis L, Krambokoukis L, Pllaha S et al (2010) Noninvasive genetic studies of brown bears using power poles. Eur J Wildl Res 56:693-702

Karamanlidis AA, de Gabriel Hernando M, Krambokoukis L, Gimenez O (2015) Evidence of a large carnivore population recovery: counting bears in Greece. J Nat Cons 27:10-17

Karamanlidis AA, de Gabriel Hernando M, Georgiadis L, Kusak J (2016) Activity, movement, home range and habitat use of an adult gray wolf in a Mediterranean landscape of northern Greece. Mammalia 81:95-99

Karamanlidis AA, Krambokoukis L, Kantiros D (2008) Challenges and problems arising from the range expansion of brown bears in Greece. Int Bear News 17:17

Karamanlidis AA, Paunovic M, Ćirovic D, Karapandža B, Skrbinšek T, Zedrosser A (2014a) Population genetic parameters of brown bears in Serbia: implications for research and conservation. Ursus 25:34-43

Karamanlidis AA, Sanopoulos A, Georgiadis L, Zedrosser A (2011) Structural and economic aspects of human-bear conflicts in Greece. Ursus 22:141-151

Karamanlidis AA, Straka M, Drosopoulou E, De Gabriel Hernando M, Kocijan I, Paule L et al (2012) Genetic diversity, structure, and size of an endangered brown bear population threatened by highway construction in the Pindos Mountains, Greece. Eur J Wildl Res 58:511-522

Karamanlidis AA, Stojanov A, de Gabriel Hernando M, Ivanov G, Kocijan I, Melovski D et al (2014b) Distribution and genetic status of brown bears in FYR Macedonia: implications for research, conservation and management. Acta Theriol 59:119-128

Karamanlidis AA, Youlatos D, Sgardelis S, Scouras Z (2007) Using sign at power poles to document presence of bears in Greece. Ursus 18:54-61

Kerr JT, Deguise I (2004) Habitat loss and the limits to endangered species recovery. Ecol Lett 7:1163-1169

Kopatz A, Eiken HG, Aspi J, Kojola I, Tobiassen C, Tirronen KF, Danilov PI, Hagen SB (2014) Admixture and gene flow from Russia in the recovering Northern European brown bear (Ursus arctos). PLoS One 9:e97558

Korkmaz EM, Sari M, Başibüyük HH (2010) Genetic structure of Chorthippus parallelus (Orthoptera: Acrididae: Gomphocerinae) populations in. Anatolia 103:625-634

Lawton JH (1993) Range, population abundance and conservation. Trends Ecol Evol 8:409-413

Le Corre V, Kremer A (1998) Cumulative effects of founding events during colonisation on genetic diversity and differentiation in an island and stepping-stone model. J Evol Biol 11:495-512

Leigh JW, Bryant D (2015) popart: full-feature software for haplotype network construction. Meth Ecol Evol 6:1110-1116

Mace RD, Waller JS (1997) Spatial and temporal interaction of male and female grizzly bears in northwesternMontana. J Wildl Manag 61:39-52

Madsen T, Shine R, Olsson M, Wittzell H (1999) Restoration of an inbred adder population. Nature 404:34-35

McLellan BN, Hovey FW (2001) Natal dispersal of grizzly bears. Can J Zool 79:838-844

Meirmans PG (2014) Nonconvergence in Bayesian estimation of migration rates. Mol Ecol Resour 14:726-733

Mona S, Ray N, Arenas M, Excoffier L (2014) Genetic consequences of habitat fragmentation during a range expansion. Heredity 112:291-299

Nei M (1978) Estimation of average heterozygosity and genetic distance from a small number of individuals. Genetics 89:583-590 
Nowak C, Domokos C, Dutsov A, Frosch C (2014) Molecular evidence for historic long-distance translocations of brown bears in the Balkan region. Cons Genet 15:743-747

Paetkau D, Strobeck C (1994) Microsatellite analysis of genetic variation in black bear populations. Mol Ecol 3:489-495

Paetkau D, Calvert W, Stirling I, Strobeck C (1995) Microsatellite analysis of population structure in Canadian polar bears. Mol Ecol 4:347-354

Paetkau D, Shields GF, Strobeck C (1998) Gene flow between insular, coastal and interior populations of brown bears in Alaska. Mol Ecol 7:1283-1292

Peakall R, Smouse PE (2006) GENALEX 6: genetic analysis in Excel. Population genetic software for teaching and research. Mol Ecol 6:288-295

Petit RJ (2011) Early insights into the genetic consequences of range expansions. Heredity 106:203-204

Pritchard JK, Stephens M, Donnelly P (2000) Inference of population structure multilocus genotype data. Genetics 155:945-959

R Core Team (2016) R: A language and environment for statistical computing. R Foundation for Statistical Computing, Vienna, Austria

Ramakrishnan AP, Musial T, Cruzan MB (2010) Shifting dispersal modes at an expanding species' range margin. Mol Ecol 19:1134-1146

Rambaut A, Drummond AJ (2003) Tracer version 1.2

Reed DH, O'Grady JJ, Brook BW, Ballou JD, Frankham R (2003) Estimates of minimum viable population sizes for vertebrates and factors influencing those estimates. Biol Cons 113:23-34

Robinson JD, Moyer GR (2013) Linkage disequilibrium and effective population size when generations overlap. Evol Appl 6:290-302

Rosenberg NA (2004) Distruct: a program for the graphical display of population structure. Mol Ecol Notes 4:137-138

Schaal BA, Leverich WJ (1996) Molecular variation in isolated plant populations. Plant Spec Biol 11:33-40

Schmitt T, Hewitt GM (2004) The genetic pattern of population threat and loss: a case study of butterflies. Mol Ecol 13:21-31

Servheen C, Herrero S, Peyton B (1999) Bears. Status Survey and Conservation Action Plan In: Groups ISBaPBS (ed) p. $\mathrm{x}+309$. IUCN, Gland, Switzerland and Cambridge, UK

Short KH, Petren K (2011) Fine-scale genetic structure arises during range expansion of an invasive gecko. PLoS ONE 6:1-9

Simpfendorfer CA (2000) Predicting population recovery rates for endangered western Atlantic sawfishes using demographic analysis. Environ Biol Fish 58:371-377

Singh HS, Gibson L (2011) A conservation success story in the otherwise dire megafauna extinction crisis: The Asiatic lion (Panthera leo persica) of Gir forest. Biol Cons 144:1753-1757

Skrbinšek T, Jelenčič M, Waits L, Kos I, Jerina K, Trontelj P (2012a) Monitoring the effective population size of a brown bear (Ursus arctos) population using new single-sample approaches. Mol Ecol 21:862-875

Skrbinšek T, Jelenčič M, Waits LP, Potočnik H, Kos I, Trontelj P. (2012b) Data and R code from: Using a reference population yardstick to calibrate and compare genetic diversity reported in different studies: an example from the brown bear. Dryad Dig Repos. DOI: https://doi.org/10.5061/dryad.qt3j5

Skrbinšek T, Jelenčič M, Waits LP, Potočnik H, Kos I, Trontelj P (2012c) Using a reference population yardstick to calibrate and compare genetic diversity reported in different studies: an example from the brown bear. Heredity 109:299-305

Sokal RR, Rohlf FJ (1994) Biometry: the principles and practice of statistics in biological research. W.H. Freeman, New York, NY
Storfer A (1999) Gene flow and endangered species translocations: a topic revisited. Biol Cons 87:173-180

Swenson JE, Adamic M, Huber D, Stokke S (2007) Brown bear body mass and growth in northern and southern Europe. Oecologia 153:37-47

Swenson JE, Sandegren F, Soderberg A (1998) Geographic expansion of an increasing brown bear population: evidence for presaturation dispersal. J Anim Ecol 67:819-826

Taberlet P, Camarra J-J, Griffin S, Uhres E, Hanotte O, Waits LP et al. (1997) Noninvasive genetic tracking of the endangered Pyrenean brown bear population. Mol Ecol 6:869-876

Traill L, Bradshaw C, Brook B (2007) Minimum viable population size: a meta-analysis of 30 years of published estimates. Biol Cons 139:159-166

Tremblay RL, Ackerman JD (2001) Gene flow and effective population size in Lepanthes (Orchidaceae): a case for genetic drift. Biol J Linn Soc 72:47-62

Upton G, Fingleton B (1985) Spatial data analysis by example. Volume 1: Point pattern and quantitative data. John Wiley \& Sons Ltd, New York, NY

Valière N (2002) GIMLET: a computer program for analysing genetic individual identification data. Mol Ecol Notes 2:377-379

van Oosterhout C, Hutchinson WF, Wills DPMS P (2004) MICROCHECKER: software for identifying and correcting genotyping errors in microsatellite data. Mol Ecol Notes 4:535-538

Vergeer P, Kunin WE (2012) Adaptation at range margins: common garden trials and the performance of Arabidopsis lyrata across its northwestern European range. New Phyt 197:989-1001

Vucetich JA, Waite TA (2003) Spatial patterns of demography and genetic processes across the species' range: Null hypotheses for landscape conservation genetics. Cons Genet 4:639-645

Wahlund S (1928) Zusammensetzung von Populationen und Korrelationserscheinungen vom Standpunkt der Vererbungslehre aus betrachtet. Hereditas 11:65-106

Waits LP, Luikart G, Taberlet P (2001) Estimating the probability of identity among genotypes in natural populations: cautions and guidelines. Mol Ecol 10:249-256

Wang J (2004) Application of the one-migrant-per-generation rule to conservation and management. Cons Biol 18:332-343

Waples RS (2002) Definition and estimation of effective population size in the conservation of endangered species. In: Beissinger SR, McCullough DR (eds) Population viability analysis. University of Chicago Press, Chicago \& London, 147-168

Waples RS (2006) A bias correction for estimates of effective population size based on linkage disequilibrium at unlinked gene loci. Conserv Genet 7:167-184

Waples RS, Do C (2008) ldne: a program for estimating effective population size from data on linkage disequilibrium. Mol Ecol Resour 8:753-756

Waples RS, Do C (2010) Linkage disequilibrium estimates of contemporary $N_{e}$ using highly variable genetic markers: a largely untapped resource for applied conservation and evolution. Evolut Appl 3:244-262

Weir BS, Cockerham CC (1984) Estimating F-statistics for the analysis of population structure. Evolution 38:1358-1370

Westemeier RJ, Brawn S, Simpson T, Esker J, Jansen J, Walk J et al. (1998) Tracking the longterm decline and recovery of an isolated population. Science 282:1695-1698

Wilson GA, Rannala B (2003) Bayesian inference of recent migration rates using multilocus genotypes. Genetics 163:1177-1191

Wright S (1964) Stochastic processes in evolution. In: Garland J (ed) Stochastic models in medicine and biology. University of Wisconsin Press, Madison, pp 199-241 